Editor's Note \& Policies

\title{
Innovation in the Wine Industry: Taking Stock and Moving Forward
}

\author{
Sergio Canavati ${ }^{1}$ \\ ${ }^{1}$ Business Administration, Sonoma State University \\ Keywords: wine innovation, wine marketing, family business, wine value, wine quality, wine emotions \\ https://doi.org/10.26813/001c.32588
}

Wine Business Journal

Vol. 5, Issue 1, 2022

\begin{abstract}
Despite the importance of innovation for survival and success of wineries around the world, research in wine industry innovation is limited. This editorial note discusses recent developments in the research of innovation in the wine industry. Special attention is given to the intersectoral nature of the wine industry, which involves agricultural, manufacturing, and marketing/sales activities. The implications of widespread family ownership and management in the wine industry for the innovation process are reviewed. Differences in how experts and consumers measure and define wine quality and value are discussed.
\end{abstract}

Despite facing severe losses and disruption from wildfires and pandemic lockdowns, the wine industry has been surprisingly resilient. According to a Silicon Valley Bank survey, 33 percent of winery owners identified the year 2020 as one of the most challenging years in their history. By the end of the year 2021, it was evident that a large segment of the industry had adapted to the new industry environment, as 29 percent of winery owners reported that 2021 was their best year ever, marking a reversal in perceived conditions relative to the prior year (McMillan, 2022). The ability of the wine industry to innovate and adapt in recent years is proof of its ability to lead through innovation in the face of increasingly volatile and hostile external conditions (Galbreath et al., 2016; Sacchelli et al., 2016; Stasi et al., 2016).

Given the importance and ubiquity of innovation in the wine industry, a large stream of research has attempted to analyze the types of innovation that exist (Gault, 2018), how to define it, and how it manifests itself, in the context of the wine industry (Porto-Gómez et al., 2020). In a pioneering effort to take stock of the existing literature on wine industry innovation, Dogru and Peyrefitte (2022) identified 76 research studies through a systematic search in academic journals and research databases. In addition to conducting a systematic literature review, Dogru and Peyrefitte (2022) are the first to use meta-analysis to aggregate the empirical evidence accumulated to date on wine industry innovation.

Textual analysis indicated that the most widely studied types of innovation (in order of frequency) are (1) "green" or eco-innovation, (2) product innovation, (3) marketing innovation, (4) process innovation, and (5) conventional [as opposed to eco-] innovation. The most common keywords in wine innovation studies are (1) wine, (2) sustainability, (3) innovation, (4) information, and (5) performance. These findings are consistent with the bibliometric review of the wine innovation literature by Porto-Gómez et al. (2020) which identified sustainable innovation as the most central type of innovation in the context of the wine industry. However, drawing inferences about a stream of studies by count- ing the number of studies that report a negative, positive, and insignificant correlation is incorrect and can lead to erroneous conclusions about the correlation between variables (Hunter \& Schmidt, 2004). As a statistical method to aggregate the findings of multiple studies, meta-analysis can provide more robust and conclusive results regarding the magnitude and direction of the relationship between two variables (Hunter \& Schmidt, 2004).

Dogru and Peyrefitte (2022) use meta-analysis to estimate the mean weighted average correlation between (a) innovation and (b) absorptive capacity, (c) technology adoption, (d) sustainable practices, and (e) export orientation across 41 studies. Regarding the mean correlations $(\bar{r})$ with winery innovation, the strongest correlation is with sustainable practices (i.e. environmental policies, data collection, eco-labeling, renewable energy use) $(\bar{r}=0.54)$. This finding provides further support for the claim that innovation in the wine industry is mainly related to innovations in winegrowing (agriculture) and winemaking (production). There is also a high degree of overlap between, on the one hand, innovation, and on the other hand, absorptive capacity (i.e. R\&D, HR quality, patents) $(\bar{r}=0.34)$ and technology adoption (i.e. winemaking machinery, automation, sensors) $(\bar{r}=0.28)$. This provides additional support for the hypothesis that innovation in the wine industry is focused on process improvements in agriculture and production. The fact that wineries' export orientation (i.e. firm exports as a percentage of total sales) has the weakest correlation with innovation $(\bar{r}=0.11)$ suggests that innovations in sales and marketing are the least relevant innovation type in the wine industry. The results of this meta-analysis also suggest a moderate correlation between winery innovation and financial performance $(\bar{r}=0.29)$.

A simple, yet powerful approach to conceptualize the intersectoral nature of innovation in the wine industry is the distinction between (1) front-end, or consumer-facing innovation (i.e. marketing/sales innovations), and (2) back-end, or agricultural and production innovations (Dressler, 2022). 
The multi-case study of four wine industry establishments in Germany by Dressler (2022) concludes that wineries commonly excel in either (1) front-end or (2) back-end innovation, but seldom excel in both areas. The results suggest that German wineries are able to overcome the tradeoff between (1) front-end and (2) back-end innovations through collaboration with industry associations and nonprofit organizations that can link different industry actors and thereby help wineries access the knowledge needed to obtain a balance between front-end and back-end innovation (Dressler, 2022).

The wine industry's disproportionate focus on innovations in agriculture (winegrowing) and production (winemaking) at the expense of innovations in sales and marketing is reflected in the disconnect between how (a) experts and (b) consumers determine wine quality and value. Wine experts' preferences in terms of varietals, tanning, aromas, and flavors tend to be correlated with those of other experts (Hopfer \& Heymann, 2014) but not with consumers' preferences (Machado, 2009). Whether the criteria used by expert raters to assess wine quality such as flavor, aroma intensity, texture, viscosity, and sugar-to-acid ratio is relevant for the sales performance of wines is questionable (Francis \& Williamson, 2015). For example, recent studies find no relationship between wine prices and wine quality as assessed by wine experts (Culbert et al., 2018; for contradictory findings see Culbert et al., 2017; Oczkowski \& Doucouliagos, 2015). Similarly, a study by Hopfer and Heymann (2014) concluded that "some consumers' liking patterns are opposite to experts' quality perceptions” (p. 231).

The importance of understanding how consumers assess the quality of the firm's wines depends on the importance management places on market success relative to its adherence to the industry's traditional standards of wine quality. A review of wine sensory evaluation research studies concluded that, regarding the "relationship between consumer liking and the quality or preference judgements of experts.... no correlation has been reported between the responses of the two groups" (Francis \& Williamson, 2015, p. 562). The discrepancy between wine experts' preferences and consumer preferences deserves further examination by wine industry managers and researchers.

The use of emotions as a measure of wine quality holds great potential for improving the relevance and accuracy of wine business research. For example, the use of self-reported, explicit measures of wine quality commonly introduces respondent bias into the survey data used by wine business research studies. Data on consumers' emotional responses to wine consumption collected through the use of implicit measures such as heart rate alterations, facial expressions, and changes in brain activity are automatic and often unconscious, which restricts the influence of respondent biases (Pedroza \& Herrell, 2022). As a novel development in wine business research methods, the use of implicit measures of wine quality provides opportunities for researchers to make empirical and theoretical contributions. Despite the benefits of implicit measures of emotions relative to explicit measures, standards and approaches for measuring and interpreting physiological responses to wine related stimuli are less established than measurement instruments for explicit measures of emotions. Thus, a mix- ture of both explicit and implicit measures of wine quality is recommended (Pedroza \& Herrell, 2022).

Managers can individualize wine tasting experiences and allow customers both on-site and remotely to learn more about their emotional reaction to the firms' wines through explicit measures of their emotional responses (i.e. surveys). Managers can also use implicit measures of wine quality to take advantage of the mass adoption of technologies that can be used to measure customers' physiological responses to wine stimuli. For example, wearable devices, tablets, and smartphones facilitate the measurement of physiological responses such as assessing facial expressions, for wineries looking to engage consumers in innovative ways by helping them learn more about how the firm's wines interact with their emotions. Of course, sensory experiences can involve more than one sense such as when customers engage their sight, smell, and taste senses during wine tastings. Wineries can proactively seek to engage additional senses through altering the research setting. For example, wineries can examine the potential effect of music or other sounds on customer engagement and purchase patterns. Data about customers' emotions before, during, and after drinking the firm's wines can be a rich source of real-world data that can help wineries be more responsive to customer needs.

When firms collect data about the preferences and feedback of customers in their industry to be more responsive to customers' needs, they can be said to engage in market-driven innovation. In comparison, market-driving innovations represent efforts to restructure the existing relationships and value configurations to envision new value propositions. A value proposition consists of creating a gain, eliminating a pain, meeting a need, or fulfilling a want or desire for a specific group of customers. Whether a segment of customers finds the value proposition(s) of the firm's products or services valuable or not depends on the unique characteristics of that group of customers and what jobs or tasks they want or need to do. Through a market-driving approach, wine industry actors can shape consumer preferences, the criteria used to determine wine value, and create new sources of value for wine consumers (Humphreys \& Carpenter, 2018).

An (2022) describes the transition from a product-dominant to a service-dominant logic in wine consumption and the role that wine documentary films played in this transition. Wine documentary films represent a form of marketdriving innovation because they created new value configurations that encouraged customers to evaluate the wine consumption process through the lenses of a service-dominant logic (An, 2022). Wine documentary films encouraged a paradigm shift from perceiving wine buying as a physical experience to conceptualizing wine consumption as an experiential purchase. In the product-dominant view, wine value disappears as consumers drink the wine, while in the service-dominant view, producers and other actors in the value chain are seen as co-creating wine value in collaboration with consumers.

Viewing wine as a service places the focus on its valuein-use during the consumer experience as opposed to its value-in-exchange, which is the traditional way of assessing wine quality through its commercial value (i.e. price). Perhaps the faltering relationship between wine experts' 
wine quality ratings and wines prices signals that what consumers value in the wine drinking experience bears no relationship to wine experts' valuation criteria and methods. It is likely that consumers' perceptions of the value-in-use of wine can be best measured through implicit and explicit measurements of customer emotional responses during the wine drinking experience. A framework to study consumers' wine experiences within a service-logic is the 4Es framework which emphasizes the importance of Esthetics, Escape, Education, and Entertainment as the sources of value for wine consumers (An, 2022; Joy et al., 2021).

While wine output and sales revenue declined during the year 2020, other alcoholic beverages such as cider saw a growth in demand and sales in the same year, including a 9 percent growth in US industry revenues (McGrath, 2021). Using a sample of 433 French participants, Le Fur and Outreville (2022) examine the preferences and drivers of cider value of young consumers. Respondents reported a preference for cider rose, suggesting young cider consumers are likely to respond favorably to new alcoholic beverages with novel flavors such as exotic fruits, vanilla, or cherry (Le Fur \& Outreville, 2022). Few young consumers know one or more cider brands, which reiterates the huge opportunities available to alcoholic beverage producers to grow through innovations in marketing and sales. The behavior of cider consumers evolves as they become more experienced and knowledgeable of cider products and brands, as respondents that are familiar with more than one cider brand are willing to pay a higher price for cider beverages of higher quality (Le Fur \& Outreville, 2022). This suggests that the traditional standards that alcoholic beverage experts use to assess quality and value may only play a significant role in shaping the preferences and purchasing behavior of highly experienced consumers, which represent only a small segment of the alcoholic beverages market.

Given that about 90 percent of wineries are familyowned and/or managed, no overview of innovation in the winery industry would be complete without a discussion of how family dynamics interact with the innovation process in this context. Woodfield and Husted (2022) criticize the traditional conceptualization of knowledge transfer in family wineries as unidirectional flowing from the senior generation (SG) to the new generation (NG). The authors argued that knowledge transfer in family firms is bidirectional because in addition to knowledge flowing from the SG to the NG, knowledge also flows from the NG to the SG. Woodfield and Husted (2022) distinguish between explicit knowledge, which can be passed on through education and codified in books and written documents, and tacit knowledge, which represents knowledge gained through experience and is difficult to capture in writing and transmit through education. An example of explicit knowledge being transferred into existing explicit knowledge occurs when the NG gains new knowledge through education and later incorporates this knowledge into the firm's existing documents and manuals in the form of training manuals, procedural documents, and formal contracts. According to Woodfield and Husted (2022), only the transfer of explicit knowledge into explicit knowledge and from tacit knowledge to explicit knowledge from the NG to the SG is likely to lead to radical innovation.
The advances in wine business theory and practice described above are encouraging, yet much work remains to be done in order to properly understand innovation in the wine industry. Despite consumer behavior and marketing being the most studied fields in the wine business literature, innovations in wine marketing and sales have received insufficient attention in comparison to innovations in winegrowing or winemaking which have received a greater deal of attention. The topic of innovation has not received enough attention in the wine business literature, which creates promising research opportunities for future studies. Furthermore, future research that synthesizes and cumulates the large number of research studies published to date in the field of wine business will help increase the relevance of wine business research for industry executives as well as for researchers in other disciplines.

\section{About the 'Ron Rubin Leading through Innovation' Special Issue}

The 'Ron Rubin Leading through Innovation' special issue was created by the Wine Business Journal to celebrate the 25th anniversary of the Wine Business Institute at Sonoma State University. Special thanks to Gary Heck whose leadership 25 years ago made the creation of the Wine Business Institute possible. This special issue is named after Ron Rubin because of his extensive and relentless commitment to advancing research, education, and awareness of the wine industry. Our advisory editors, Edwin Adams, Vicky Farrow, Anisya Fritz, and Jon Moramarco, invested countless hours to provide direction and vision for this special issue.

We conclude by recognizing the exceptional efforts of the authors and reviewers who contributed to this special is sue. While only six studies were published, we are grateful to the authors of all 15 submissions to this special issue. We are glad to announce that the board of directors of the Wine Business Institute selected the study titled "Investigation of Innovation in Wine Industry via Meta-Analysis" (Dogru \& Peyrefitte, 2022) as the winner of the best paper award for this special issue. In addition, the editorial board of the Wine Business Journal is proud to recognize the manuscript titled "Exploring Emotions as a New Quality Parameter in Wine” (Pedroza \& Herrell, 2022) as a groundbreaking contribution that will influence the discussion of wine quality measurement in the near future. The editorial board also selected the study titled "Innovation Management in Wine Business - Need to Address Front-End, Back-End, or Both?" (Dressler, 2022) as the best international submission to this special issue. This special issue was made possible by the vision and leadership of Ray Johnson, director of the Wine Business Institute and associate editor Matthew Bauman. We close this special issue introduction by recognizing the effort and dedication of the reviewers who invested countless hours to provide invaluable feedback for the manuscripts submitted to the special issue. In particular, we would like to recognize Jean Dodson Peterson as the best reviewer of 2021 for her outstanding effort to submit countless rigorous reviews in a most timely fashion. 
The researchers and wine industry experts who served as reviewers for the manuscripts submitted to this special issue are listed below:

- Jared Allen, Texas Tech University

- Tom Atkin, Sonoma State University

- Mary Barrett, University of Wollongong

- Xian Cao, Ball State University

- Adam Carmer, University of South Florida

- Armando Corsi, University of Adelaide

- James Crick, University of Leicester

- Jean Dodson Peterson, California Polytechnic State University, San Luis Obispo

- Hannah DeYoung, Sonoma State University

- Marc Dressler, Hochschule Ludwigshafen
- Vicky Farrow, Amista Vineyards

- Anisya Fritz, Lynmar Estate

- Robert Harrington, Washington State University

- Jean Hertzman, New Mexico State University

- Dirk Libaers, University of South Florida

- Matthew McSweeney, Acadia University

- Sandra Newton, Sonoma State University

- Ivan Paunovic, Bonn-Rhein-Sieg University

- Miguel A. Pedroza, California State University, Fresno

- Dennis Reynolds, University of Houston

- Emiliano Villanueva, Eastern Connecticut State University 


\section{References}

An, J. (2022). Examining market-driving innovation in the wine industry: A topic modeling method on consumer reviews on wine documentaries. Wine Business Journal, 5(1), 1-11. https://doi.org/10.26813/ $\underline{001 c .31306}$

Culbert, J. A., Ristic, R., Ovington, L. A., Saliba, A. J., \& Wilkinson, K. L. (2017). Influence of production method on the sensory profile and consumer acceptance of Australian sparkling white wine styles. Australian Journal of Grape and Wine Research, 23(2), 170-178. https://doi.org/10.1111/ajgw.12277

Culbert, J. A., Ristic, R., Ovington, L. A., Saliba, A. J., \& Wilkinson, K. L. (2018). Sensory profiles and consumer acceptance of different styles of Australian Moscato. Australian Journal of Grape and Wine Research, 24(1), 96-104. https://doi.org/10.1111/ajg w. 12300

Dogru, A., \& Peyrefitte, J. (2022). Investigation of innovation in wine industry via meta-analysis. Wine Business Journal, 5(1), 1-33. https://doi.org/10.26813/ $\underline{001 c .31627}$

Dressler, M. (2022). Innovation management in wine business - Need to address front-end, back-end, or both? Wine Business Journal, 5(1), 1-17. https://doi.or g/10.26813/001c.31770

Galbreath, J., Charles, D., \& Oczkowski, E. (2016). The drivers of climate change innovations: Evidence from the Australian wine industry. Journal of Business Ethics, 135(2), 217-231. https://doi.org/10.1007/s1055 1-014-2461-8

Gault, F. (2018). Defining and measuring innovation in all sectors of the economy. Research Policy, 47(3), 617-622. https://doi.org/10.1016/j.respol.2018.01.007

Hopfer, H., \& Heymann, H. (2014). Judging wine quality: Do we need experts, consumers or trained panelists? Food Quality and Preference, 32, 221-233. https://do i.org/10.1016/i.foodqual.2013.10.004

Humphreys, A., \& Carpenter, G. S. (2018). Status games: Market driving through social influence in the US wine industry. Journal of Marketing, 82(5), 141-159. ht tps://doi.org/10.1509/jm.16.0179

Hunter, J., \& Schmidt, F. (2004). Methods of metaanalysis: Correcting error and bias in research findings. Sage. https://doi.org/10.4135/9781412985031
Joy, A., Yoon, S., Grohmann, B., \& LaTour, K. (2021). How winery tourism experience builds brand image and brand loyalty. Wine Business Journal, ,1-18. http s://doi.org/10.26813/001c.30210

Le Fur, E., \& Outreville, J. F. (2022). The willingness to pay for cider products: Results of a survey on habits and consumption behavior. Wine Business Journal, 5(1), 1-14.

Machado, B. (2009). Revealing the secret preferences for top-rated dry red wines through sensometrics [Master's Thesis,]. University of California at Davis.

McGrath, M. (2021). Cider's resilience stood true through 2020. American Cider Association. https://ciderassoci ation.org/ciders-resilience-stood-true-through-2020/

McMillan, R. (2022). State of the US wine industry 2022. Silicon Valley Bank Financial Group. https://www.sv b.com/globalassets/trendsandinsights/reports/wine/s vb-state-of-the-wine-industry-report-2022.pdf

Pedroza, M. A., \& Herrell, R. (2022). Exploring emotions as a new quality parameter in wine. Wine Business Journal, 5(1), 1-20. https://doi.org/10.26813/001c.316 $\underline{63}$

Porto-Gómez, I., Larreina, M., \& Gaviria-de-la-Puerta, J. (2020). Does wine innovation research require ageing? A bibliometric review. Profesional de la Información, 29(6), 290615. https://doi.org/10.3145/ep i.2020.nov. 15

Sacchelli, S., Fabbrizzi, S., \& Menghini, S. (2016). Climate change effects and adaptation strategies in the wine sector: A quantitative literature review. Wine Economics and Policy, 5(2), 114-126. https://doi.org/1 0.1016/j.wep.2016.08.001

Stasi, A., Muscio, A., Nardone, G., \& Seccia, A. (2016). New technologies and sustainability in the Italian wine industry. Agriculture and Agricultural Science Procedia, 8, 290-297. https://doi.org/10.1016/j.aaspr $\underline{0.2016 .02 .023}$

Woodfield, P. J., \& Husted, K. (2022). Sharing knowledge across generations and its impact on innovation. Wine Business Journal, 5(1), 1-16. https://doi.org/10.2 6813/001c.31022 